\title{
Use of Leaf Wetness and Temperature to Time Fungicide Applications to Control Botrytis Fruit Rot of Strawberry in Florida
}

\author{
S. J. MacKenzie and N. A. Peres, University of Florida, Gulf Coast Research and Education Center, Wimauma 33598
}

\begin{abstract}
MacKenzie, S. J., and Peres, N. A. 2012. Use of leaf wetness and temperature to time fungicide applications to control Botrytis fruit rot of strawberry in Florida. Plant Dis. 96:529-536.

Botrytis fruit rot (BFR), caused by Botrytis cinerea, is a major disease of strawberry in Florida and is generally controlled by weekly fungicide applications. In this study, disease control programs using fungicides applied on a weekly basis were compared with applications based on three previously published models that correlated disease incidence with weather variables. Field trials were conducted for three seasons on two cultivars, 'Sweet Charlie' and 'Strawberry Festival'. Different thresholds for predicted BFR incidence were evaluated for triggering fungicide applications for the three models. BFR incidence in nontreated control plots of Sweet Charlie and Strawberry Festival was 12.4 and $3.5 \%$, respectively, in 2006-07, 4.2 and $0.8 \%$ in 200708 , and 1.3 and $0.5 \%$ in 2008-09. The model of Bulger and associates, with a threshold for disease flower incidence $\left(I N F_{B u}\right)$ of 0.50 , triggered

grower program, without significantly increasing BFR incidence or reducing yield. The model of Broome and associates, at a predicted fruit disease incidence threshold $\left(I N F_{B r}\right)$ of 0.62 , performed well but required more fungicide applications than the Bulger model $\left(I N F_{B u} \geq\right.$ 0.50 ). The model of $\mathrm{Xu}$ and associates, based on field data to predict the incidence of diseased flowers, required more fungicide applications without improving disease control. Use of higher thresholds resulted in fewer applications but increased disease incidence in some cases. The Bulger model utilizing leaf wetness and temperature during the wetness period as input variables and a threshold of $I N F_{B u}$ of 0.50 can be used effectively in a disease-forecasting system to time fungicide treatments, and greatly reduced the number of applications without loss of disease control or yield.
\end{abstract} half or fewer fungicide applications compared with a calendar-standard
Strawberries are grown as an annual crop in Florida (8). Each season, transplants produced in Canada or other cooler climates are established in fumigated beds covered with plastic mulch from late September to mid-October. Flower production begins in November and lasts throughout the season. The main peak bloom period begins in late January and continues through February (14) and fruit from this flowering period mature from late February until the season ends in March (6). Botrytis fruit rot (BFR), or gray mold, caused by Botrytis cinerea, and anthracnose fruit rot, caused by Colletotrichum acutatum, are the major diseases of fruit in the region. Fungicide application costs to control these two diseases represent nearly $15 \%$ of the total operating costs each growing season.

BFR is primarily a problem in production fields but can also be a postharvest disease (20). Infection of strawberry flowers and fruit by $B$. cinerea is usually initiated by conidia produced on dead strawberry foliage (3). B. cinerea forms quiescent infections on young strawberry leaves and, subsequently, colonizes the leaf tissue upon senescence (3). Conidia from senescent tissues are dispersed by wind, rain, or harvesters and fruit infections are initiated at the flowering stage $(4,13,20)$. Fruit may not show BFR symptoms until they begin to ripen or are fully ripe, which may be up to 4 weeks after infection. Direct infection of fruit by conidia is not considered important, although the disease can spread to mature, healthy fruit when in contact with infected fruit, petals, or other tissues $(19,20)$. After an epidemic begins, diseased fruit and senes-

Corresponding author: N. A. Peres, E-mail: nperes@ufl.edu

Mention of trade names or commercial products in this article is solely for the purpose of providing scientific information and does not imply recommendation or endorsement by the University of Florida.

Accepted for publication 27 October 2011.

http://dx.doi.org/10.1094/PDIS-03-11-0182

(C) 2012 The American Phytopathological Society cent foliage are both important sources of secondary inoculum (20). Temperatures close to the optimum for infection, approximately $20^{\circ} \mathrm{C}(7)$, and prolonged periods of wetness are most conducive to disease development.

Numerous studies have shown that applying fungicides to flowers is the best way to control BFR $(10,13,21)$ because most infections occur at this stage. Recommended control for BFR as well as anthracnose fruit rots in Florida was based on weekly applications of protectant fungicides such as captan or thiram at the full rate in addition to application of systemic fungicides during peak bloom, when disease incidence and yields were greatest (11). Subsequently, Legard et al. (10) demonstrated that reduced rates of protectant fungicides could be used early in the season when the risk of disease development was lower and that fenhexamid, a systemic and more effective fungicide, could be used only during the main peak bloom. Fenhexamid (Elevate) is one of the most effective systemic fungicides for controlling BFR (15) but the number of applications is limited to four per season (10). Thus, the current recommendation for controlling BFR in Florida is to apply fenhexamid or other systemic fungicides effective against BFR that have restrictions on usage such as pyraclostrobin + boscalid (Pristine), cyprodinil + fludioxonil (Switch), and pyrimethanil (Scala) during the 4 weeks of the main peak bloom from late January to mid-February $(10,14)$. At other times during the season, weekly applications of protectant fungicides, such as captan or thiram, continue to be recommended $(11,14)$.

Models to predict the incidence of $B$. cinerea affecting strawberry flowers and fruit rot originating from infected flowers as a function of wetness duration and temperature were developed by Bulger et al. (7) in experiments under controlled conditions using 'Midway' strawberry. The authors stated that the models could be useful in determining the risk of development of flower infections leading to fruit infection under natural conditions but their validity in the field have not been tested.

Broome et al. (5) have also developed a model under controlled conditions for Botrytis bunch rot of grape based on wetness duration and temperature during a wetness interval to predict the incidence of grape berry infection. The model was evaluated in the 
field for two seasons and compared with a standard spray program. Disease incidence and severity of grape bunch rot was similar for both programs but fewer applications were made with the model program.

Another set of models has been developed by Xu et. al. (23) from field data collected in the United Kingdom for 'Elsanta' strawberry. The models were developed to predict the incidence of strawberry flower infection by using only inoculum, only weather variables, or both. The model using only weather variables was more accurate than the one using only inoculum and as good as the one based on both weather and inoculum. Weather variables used were daytime vapor point deficit, nighttime temperature, and the total duration of the surface wetness over a period preceding the interval where daytime vapor point deficit was calculated. The authors evaluated whether the weather-based model could assist in managing BFR in the field and found promising results (2).

In Florida, these models cannot be used to predict disease incidence in the field because the parameters in the models were derived from studies on a different host species or strawberry cultivars that are not planted currently in production fields. Also, several of the models were constructed from inoculations using only a single spore concentration or were conducted in the laboratory. However, although infection efficiencies might not be the same, conidial germination and fungal growth would likely be the same on the different cultivars and the models could be used to establish threshold conditions where disease outbreaks might occur.

In this study, we evaluated the usefulness of the models developed by Bulger et al. (7), Broome et al. (5), and Xu et al. (23) to schedule fungicide applications for three seasons on two cultivars under Florida conditions. We found that the number of fungicide applications for BFR control can be reduced to fewer than half of the number used in the standard calendar program without loss of disease control or yield. A preliminary report of this study has been published previously (17).

\section{Materials and Methods}

Plant materials, cultivation, and plot layout. The strawberry cultivars Sweet Charlie and Strawberry Festival were established from bare-root transplants from Canadian nurseries at the beginning of the 2006-07, 2007-08, and 2008-09 seasons. The strawberry plants were transplanted into plastic-mulch covered, raised beds at the Gulf Coast Research and Education Center in Wimauma, FL on 16 October (both cultivars) in 2006; 17 October (both cultivars) in 2007; and 7 October ('Strawberry Festival') and 14 October ('Sweet Charlie') in 2008. Beds were $91.4 \mathrm{~m}$ long, 71 $\mathrm{cm}$ wide, $18 \mathrm{~cm}$ high at the center, and $15 \mathrm{~cm}$ high at the edges. The distance between bed centers was $1.2 \mathrm{~m}$. Each bed contained two staggered rows of plants spaced $30 \mathrm{~cm}$ apart between rows and $38 \mathrm{~cm}$ apart within rows. Prior to transplant, beds were fumigated with methyl bromide:chloropicrin (67:33) for the 2006-07 season, methyl bromide:chloropicrin (98:2) for the 2007-08 season, and methyl bromide:chloropicrin (50:50) for the 2008-09 season. Transplants were irrigated by overhead sprinklers for 10 to 12 days to facilitate establishment, and were irrigated and fertilized through drip tape once plants were established. Fields were scouted for invertebrate pests and appropriate treatments made when pests reached threshold populations. Freeze protection was provided by overhead sprinklers when necessary.

A group of four adjacent beds was planted with 'Sweet Charlie' and a second group of four adjacent beds was planted with 'Strawberry Festival'. An empty bed separated the two cultivars. Each plot contained 20 plants and there were 3.4-m long gaps between plots. Plots on separate beds were staggered so that there were no plants on each side of the plots. Treatments were arranged in a completely randomized design with four replications (beds).

Weather monitoring and model to predict disease severity. All equipment used for weather monitoring was from Campbell Scientific, Inc., Logan, UT. Weather data were taken at 15-min intervals using a CR23X micrologger. Temperature and relative humidity data were obtained from two CS500 shielded temperature and relative humidity probes, wetness data were collected from two latex-painted model 237 leaf-wetness sensors, and rainfall data were collected from a CS700-L rain gauge. Wetness, temperature, and relative humidity probes were placed on a bed at canopy height between strawberry plants. The rain gauge was placed at the edge of the strawberry field. The resistance for leaf wetness sensors at the wet-dry transition was $500 \mathrm{k} \Omega$. If there was a conflict between leaf wetness sensor outputs, a period was considered wet if the relative humidity, as measured by the mean output of two probes, exceeded $95 \%$.

Inputs into the Bulger et al. (7) and Broome et al. (5) models were the length of a wetness interval in the field $(W)$ and the mean temperature $(T)$ during the wetness interval. Wetness intervals continued to proceed after gaps of less than $4 \mathrm{~h}$ of dryness but time accumulation and temperature measurements during intermittent dry periods of less than $4 \mathrm{~h}$ were not included in the determination of the length of a wetness interval or in the mean temperature $(T)$ during the wetness interval. Equation 5 of Bulger et al. (7) to predict Botrytis spp. incidence on strawberry flowers was $\ln \left(I N F_{B u} /[1\right.$ $\left.\left.-I N F_{B u}\right]\right)=-4.268+0.0294 W T-0.0901 W-0.0000235 W T^{3}$. The equation of Broome et al. (5) to predict Botrytis bunch rot infection on grape was $\ln \left(I N F_{B r} /\left[1-I N F_{B r}\right]\right)=-2.648-0.3749 W+$ $0.0616 W T-0.0015 W T^{2}$. A value for predicted disease incidence was calculated for each day based on weather averages that were calculated from noon to noon.

In the model of $\mathrm{Xu}$ et al. (23), the incidence of flower infection was modeled using the input variables daytime vapor point deficit $(v p d)$, nighttime temperature $\left(n t_{1}\right)$, and total duration of the surface wetness the previous night $\left(n w_{-1}\right)$. Mean daytime temperature $(T)$ and relative humidity $(r h)$ were determined over the interval from 8:00 a.m. to 7:45 p.m. the day prior to calculation of flower infection incidence. Mean temperature and relative humidity were used subsequently to determine vpd (in $\mathrm{mm} \mathrm{Hg}$ ) using the following equation $v p d=4.6698 e^{0.06241 \mathrm{t}}(1-\mathrm{rh} / 100)$. The variable $n t_{1}$ was the mean temperature over the interval from 8:00 p.m. to 7:45 a.m. that occurred just before calculation of the flower infection incidence, and the variable $n w_{-1}$ was the cumulative hours of wetness over the same interval for the preceding night. Equation 3 to estimate BFR incidence using only weather variables for the $\mathrm{Xu}$ et al. (23) model was $\ln \left(I N F_{X u} /\left[1-I N F_{X u}\right]\right)=-3.78-0.28 v p d+0.41 n t_{1}-0.12 n w_{-1}$. Subsequently, in this report, these models are referred to as the Bulger, Broome, and Xu models.

Fungicide selection. Fungicides used for the field tests were captan and fenhexamid. Captan (Captan 80WDG; Micro Flo Company LLC, Memphis, TN) was applied at $1.65 \mathrm{~kg}$ a.i./ha (low rate) up to the beginning of the late-season peak bloom and at $2.63 \mathrm{~kg}$ a.i./ha (high rate) once the late-season peak bloom began. Fenhexamid was generally applied in combination with captan (CaptEvate 68WDG; Arysta Lifescience, Cary, NC; captan at 2.63 $\mathrm{kg}$ a.i./ha and fenhexamid at $0.7 \mathrm{~kg}$ a.i./ha). In some instances, fenhexamid was applied alone at $0.7 \mathrm{~kg}$ a.i./ha (Elevate 50WDG; Arysta Lifescience, Cary, NC).

Fungicide application programs. All fungicide treatment programs applied during the 2006-07, 2007-08, and 2008-09 seasons are listed in Table 1. In all three seasons, there was a nonsprayed treatment and two calendar application treatments that began on 15, 27, and 19 November in the 2006-07, 2007-08, and 2008-09 seasons, respectively. The final calendar applications were on 28 February, 11 March, and 11 March in the 2006-07, 2007-08, and 2008-09 seasons, respectively. One calendar application program included only captan (treatment 2), whereas the other included captan + fenhexamid during the peak bloom that begins in late January or early February in Florida (treatment 3). The first fenhexamid treatment was applied at the start of the peak bloom and followed by three additional fenhexamid applications and, subsequently, high-rate captan applications for the remainder of the season.

Model-timed fungicide applications were based on the Bulger, Broome, and $\mathrm{Xu}$ disease infection models described above, with 
different thresholds used to trigger applications. During the first two seasons (2006-07 and 2007-08), all three models were used to time applications and, for each model, two different thresholds were evaluated to trigger applications. Thresholds were based on the predicted proportion of fruit or flowers infected (INF) from model equations. The lower threshold for the $\mathrm{Xu}$ and Bulger models was 0.50 and, for the Broome model, it was 0.62. The 0.50 INF threshold for the $\mathrm{Xu}$ and Bulger models was based on the observation that increases in fruit rot incidence occurred only marginally until the incidence of petal infection exceeded $50 \%(7,23)$. The association between the incidence of flower infection and fruit rot reported by Bulger et al. (7) was based on inoculated flowers, and we assumed that the weather conditions that give $50 \%$ infection of flowers would be the threshold where fruit rot incidence began to rise. The $\mathrm{Xu}$ model has been evaluated to time fungicide applications in the United Kingdom using a fruit rot infection threshold of 0.10 , which corresponds to an $I N F_{X u}=0.54$ (2). Broome et al. (5) reported that infection intervals for Botrytis bunch rot of grape of moderate risk or greater were observed when $I N F_{B r} \geq 0.62$. Two preliminary trials conducted in the 2004-05 and 2005-06 seasons indicated that triggering sprays with the low threshold using the Broome and $\mathrm{Xu}$ models would reduce sprays, on average, by approximately $40 \%$ (17). Analysis of weather data from the five seasons that preceded the 2006-07 season indicated that using the 0.5 threshold for the Bulger model would have also reduced sprays by approximately $40 \%$. Fungicides were applied when the set thresholds for each model were surpassed and a minimum of 7 days was considered between fungicide applications.

In treatments 4,6 , and 8 , the captan or captan + fenhexamid applications were timed to infection periods that exceeded lower thresholds only. In these treatments, captan + fenhexamid was applied if an application was triggered by a model during the 4-week peak bloom period and captan was applied alone at all other times.

In treatments 5, 7, and 9, captan + fenhexamid applications were timed to infection periods that exceeded high thresholds only. The high disease thresholds for the $\mathrm{Xu}$, Broome, and Bulger models were $0.80,0.80$, and 0.70 , respectively. The high threshold values for the Broome and Bulger models were determined empirically from weather data from the five seasons preceding the 2006-07 season. Based on the weather during those seasons, timing applications to the higher threshold for the Broome and Bulger models would have reduced applications by 60 to $70 \%$. The higher threshold for the $\mathrm{Xu}$ model was set based on our experience using this model, and expected reductions in fungicide usage at the higher threshold were not determined prior to use. For treatments 5 and 7 that timed fungicide applications to the higher threshold using the $\mathrm{Xu}$ and the Broome models, captan + fenhexamid was applied if an application was triggered by a model during the 4-week peak bloom period and captan was applied alone at all other times. For treatment 9 that timed applications to the higher threshold using the Bulger model, captan + fenhexamid was applied when an application was triggered so as to apply fenhexamid at times throughout the season when conditions were particularly conducive to BFR development, regardless of the bloom stage.

During the 2006-07 and 2007-08 seasons, a dual-threshold treatment (treatment 10) was also evaluated, in which captan was applied at the lower Bulger model threshold, when conditions were moderately favorable for infection, and captan + fenhexamid was applied at the high threshold, when conditions were more conducive for infection. A similar treatment (treatment 11) was evaluated in 2008-09, in which a dual threshold was used where captan was applied early in the season if the lower threshold was exceeded and captan + fenhexamid if the higher threshold was exceeded. However, from peak bloom until the end of the season, captan + fenhexamid was applied when either threshold was exceeded, and this continued until four applications of this mixture were applied, after which captan was applied for the remainder for the season when either threshold was exceeded. This treatment was designed to allow fenhexamid to be applied during the most conducive times, as triggered by the weather early in the season, and during moderately conducive weather events late in the season, when the plant canopy was large and flower numbers were greatest.

Treatment 12, applied only during the 2008-09 season, used forecast values of weather variables to schedule applications according to the $I N F_{B u}$ from the Bulger model. The disease incidence forecast was based on the next-day hourly humidity and temperature forecasts for Wimauma, FL from the United States National Weather Service. An hourly interval was determined to be wet if

Table 1. Treatments applied during 2006-07 (season 1), 2007-08 (season 2), and 2008-09 (season 3) for control of Botrytis fruit rot of strawberry in Florida

\begin{tabular}{|c|c|c|}
\hline \multirow[b]{2}{*}{ Treatment number, description (seasons) ${ }^{\mathrm{z}}$} & \multicolumn{2}{|c|}{ Fungicide application criteria ${ }^{y}$} \\
\hline & Early season & Peak bloom and later \\
\hline 1. Nontreated control (1,2 and 3$)$ & None & None \\
\hline 2. Cal, captan (1, 2 and 3$)$ & Captan, low applied weekly & Captan, high applied weekly \\
\hline $\begin{array}{l}\text { 3. Cal, captan or fenhexamid + captan } \\
(1,2 \text { and } 3)\end{array}$ & Captan, low applied weekly & $\begin{array}{l}\text { Four applications of fenhexamid }+ \text { captan applied weekly } \\
\text { beginning at peak bloom followed by weekly applications of } \\
\text { captan, high to end of season }\end{array}$ \\
\hline 4. Mod, Xu at $I N F_{X u} \geq 0.50(1$ and 2) & Captan, low if $I N F_{X u} \geq 0.50$ & $\begin{array}{l}\text { Fenhexamid + captan if } I N F_{X u} \geq 0.50 \text { first } 4 \text { weeks into peak } \\
\text { bloom, captan, high if } I N F_{X u} \geq 0.50 \text { to end of season }\end{array}$ \\
\hline 5. Mod, Xu at $I N F_{X u} \geq 0.80(1$ and 2) & Captan, low if $I N F_{X u} \geq 0.80$ & $\begin{array}{l}\text { Fenhexamid + captan if } I N F_{X u} \geq 0.80 \text { first } 4 \text { weeks into peak } \\
\text { bloom, captan }\left(2.63 \mathrm{~kg} \text { a.i./ha) if } I N F_{X u} \geq 0.80 \text { to end of }\right. \\
\text { season }\end{array}$ \\
\hline 6. Mod, Broome at $I N F_{B r} \geq 0.62$ (1 and 2) & Captan, low if $I N F_{B r} \geq 0.62$ & $\begin{array}{l}\text { Fenhexamid }+ \text { captan if } I N F_{B r} \geq 0.62 \text { first } 4 \text { weeks into peak } \\
\text { bloom, captan, high if } I N F_{B r} \geq 0.62 \text { to end of season }\end{array}$ \\
\hline 7. Mod, Broome at $I N F_{B r} \geq 0.80$ (1 and 2) & Captan, low if $I N F_{B r} \geq 0.80$ & $\begin{array}{l}\text { Fenhexamid + captan if } I N F_{B r} \geq 0.80 \text { first } 4 \text { weeks into peak } \\
\text { bloom, captan, high if } I N F_{B r} \geq 0.80 \text { to end of season }\end{array}$ \\
\hline 8. Mod, Bulger at $I N F_{B u} \geq 0.50(1,2$ and 3) & Captan, low if $I N F_{B u} \geq 0.50$ & $\begin{array}{l}\text { Fenhexamid + captan if } I N F_{B u} \geq 0.50 \text { first } 4 \text { weeks into peak } \\
\text { bloom, captan, high if } I N F_{B u} \geq 0.50 \text { to end of season }\end{array}$ \\
\hline 9. Mod, Bulger at $I N F_{B u} \geq 0.70$ (1 and 2) & Fenhexamid + captan if $I N F_{B u} \geq 0.70$ & $\begin{array}{l}\text { Fenhexamid + captan if } I N F_{B u} \geq 0.70 \text { until four applications } \\
\text { of fenhexamid, then captan, high if } I N F_{B u} \geq 0.70\end{array}$ \\
\hline $\begin{array}{l}\text { 10. Mod, Bulger at } I N F_{B u} \geq 0.50 \text { and } 0.70 \\
\text { (1 and 2) }\end{array}$ & $\begin{array}{l}\text { Captan, low if } I N F_{B u} \geq 0.50 \text {, fenhexamid } \\
\text { or fenhexamid + captan if } I N F_{B u} \geq 0.70\end{array}$ & $\begin{array}{l}\text { Captan, high if } I N F_{B u} \geq 0.50 \text {, fenhexamid or fenhexamid + } \\
\text { captan if } I N F_{B u} \geq 0.70\end{array}$ \\
\hline 11. Mod, Bulger at $I N F_{B u} \geq 0.50$ and 0.70 (3) & $\begin{array}{l}\text { Captan, low if } I N F_{B u} \geq 0.50 \text {, fenhexamid } \\
\text { or fenhexamid + captan if } I N F_{B u} \geq 0.70\end{array}$ & $\begin{array}{l}\text { Fenhexamid + captan if } I N F_{B u} \geq 0.50 \text { until four applications } \\
\text { of fenhexamid, then captan, high if } I N F_{B u} \geq 0.50\end{array}$ \\
\hline $\begin{array}{l}\text { 12. Mod to forecasted wetness interval, } \\
\text { Bulger at } I N F_{\text {forecast }} \geq 0.50 \text { (3) }\end{array}$ & $\begin{array}{l}\text { Captan, low if } I N F_{\text {forecast }} \geq 0.50, \\
\text { fenhexamid }+ \text { captan if } I N F_{B u} \geq 0.70 \text { and } \\
\text { no captan applied within } 7 \text { days }\end{array}$ & $\begin{array}{l}\text { Captan, high if } I N F_{\text {forecast }} \geq 0.50, \text { fenhexamid }+ \text { captan if } \\
I N F_{B u} \geq 0.70 \text { and no captan applied within } 7 \text { days }\end{array}$ \\
\hline
\end{tabular}

${ }^{\mathrm{y}}$ Fungicide rates were Captan, high $=2.63 \mathrm{~kg}$ a.i. $/ \mathrm{ha}$; Captan, low $=1.65 \mathrm{~kg}$ a.i. $/ \mathrm{ha}$; fenhexamid $=0.7 \mathrm{~kg}$ a.i. $/ \mathrm{ha}$; and fenhexamid + captan $=$ fenhexamid at $0.7 \mathrm{~kg}$ a.i./ha and captan at $2.63 \mathrm{~kg} / \mathrm{ha}$.

${ }^{\mathrm{z}}$ Treatment number, description, and seasons applied. $\mathrm{Cal}=$ calendar; $\mathrm{Mod}=$ model-timed; and $\mathrm{Xu}$, Broome, and Bulger $=$ names of models used. 
forecasted relative humidity exceeded $85 \%$. Captan was applied to plots if $I N F_{\text {forecast }} \geq 0.50$, the lower threshold for the Bulger model. If captan had not been applied for 7 days and the $I N F_{B u}$ predicted from actual weather data exceeded 0.70 , then captan + fenhexamid was applied. Infection intervals where captan + fenhexamid could be applied included times when a forecast was missed before an infection interval highly conducive to BFR development.

For all of the timed treatments described, the same fungicide could not be applied more than once during a 7-day period.

Data collection and statistical analysis. Fruit were harvested twice weekly from 6 December 2006 to 2 March 2007 for 'Sweet Charlie' and from 6 December 2006 to 13 March 2007 for 'Strawberry Festival' during the 2006-07 season. For both cultivars, fruit were harvested from 11 December 2007 to 18 March 2008 for the 2007-08 season and from 2 December 2008 to 13 March 2009 for the 2008-09 season. At each harvest, fruit were sorted into marketable and unmarketable groups. Fruit were culled and designated unmarketable if they were diseased or weighed less than $10 \mathrm{~g}$. Subsequently, total numbers of marketable fruit, culled fruit, fruit with BFR symptoms, and fruit with anthracnose fruit symptoms were recorded along with the weight of marketable fruit for each plot. At the end of the season, data taken from each harvest date were summed. Statistical analyses were conducted to determine whether marketable yield and the percentage of fruit with BFR were different between treatments. Data from each season-cultivar combina- tion were analyzed separately using PROC MIXED of SAS (SAS Institute, Cary, NC). Fungicide treatment was considered a fixed effect and replicate a random effect. Overall treatment effects were evaluated with $F$ statistics and differences between fungicide treatments were evaluated using the LSMEANS statement and PDIFF option if the overall treatment effect was significant at $P \leq 0.05$. Statistical analyses were conducted on arcsine square-root-transformed proportions, as opposed to percentages, to normalize distribution across treatments. The formula for the transformation was $\arcsin \{\operatorname{sqrt}[(y+3 / 8) /(n+3 / 4)]\}$, where $y=$ the number of fruit with BFR per plot and $n=$ the total number of fruit harvested (1). Mean percentages are reported in tables along with the mean of transformed proportions.

\section{Results}

BFR incidence. BFR incidence in nontreated control plots (treatment 1) each season for 'Sweet Charlie' and 'Strawberry Festival' was 12.4 and $3.5 \%$, respectively, in 2006-07, 4.2 and $0.8 \%$ in $2007-08$, and 1.3 and $0.5 \%$ in 2008-09. For disease incidence, $F$ statistics of overall treatment effects for each cultivar within seasons were significant at $P \leq 0.05$ in three of the six season-cultivar trials. In these three trials with significant overall effects, disease incidence among treatments on Sweet Charlie in 2006-07 and 2007-08 and on Strawberry Festival in 2006-07 was examined (Table 2). These three season-cultivar trials had the three

Table 2. Effect of calendar and model-timed fungicide application programs on incidence of Botrytis fruit rot (BFR) and marketable yield in the 2006-07, 2007-08, and 2008-09 seasons

\begin{tabular}{|c|c|c|c|c|c|c|c|c|}
\hline \multirow[b]{3}{*}{ Season, treatment ${ }^{\mathrm{z}}$} & \multirow{2}{*}{\multicolumn{4}{|c|}{ Number of fungicide applications ${ }^{y}$}} & \multicolumn{4}{|c|}{ Cultivar $^{x}$} \\
\hline & & & & & \multicolumn{2}{|c|}{ 'Sweet Charlie' } & \multicolumn{2}{|c|}{ 'Strawberry Festival' } \\
\hline & Cap & Fen & Cap + Fen & Total & BFR \% (arcsin) & $\overline{\text { Yield (g/plot) }}$ & BFR \% (arcsin) & Yield (g/plot) \\
\hline \multicolumn{9}{|l|}{$2006-07$} \\
\hline 3. Cal, Cap or Fen + Cap & 12 & $\ldots$ & 4 & 16 & $4.05(0.200) \mathrm{a}$ & $7,900 \mathrm{bc}$ & $0.46(0.071) \mathrm{a}$ & 9,994 \\
\hline 10. Mod, Bulger at $I N F_{B u} \geq 0.50$ and 0.70 & 4 & $\cdots$ & 4 & 8 & $4.28(0.206) \mathrm{a}$ & $8,725 \mathrm{ab}$ & $1.08(0.106) \mathrm{bc}$ & 10,432 \\
\hline 6. Mod, Broome at $I N F_{B r} \geq 0.62$ & 7 & $\ldots$ & 2 & 9 & $4.45(0.206) \mathrm{a}$ & $8,334 \mathrm{ab}$ & $1.01(0.101) b c$ & 10,246 \\
\hline 2. Cal, Cap & 16 & $\ldots$ & $\ldots$ & 16 & $4.71(0.217) \mathrm{a}$ & $8,767 \mathrm{ab}$ & $0.85(0.091) \mathrm{ab}$ & 10,459 \\
\hline 8. Mod, Bulger at $I N F_{B u} \geq 0.50$ & 7 & $\ldots$ & 1 & 8 & $4.83(0.218) \mathrm{a}$ & $8,580 \mathrm{ab}$ & $1.20(0.112) \mathrm{bc}$ & 10,404 \\
\hline 4. Mod, Xu at $I N F_{X u} \geq 0.50$ & 9 & $\ldots$ & 3 & 12 & $5.18(0.230) \mathrm{ab}$ & $8,955 \mathrm{a}$ & $1.57(0.127) \mathrm{c}$ & 10,303 \\
\hline 5. Mod, Xu at $I N F_{X u} \geq 0.80$ & 8 & $\ldots$ & 2 & 10 & $6.28(0.254) \mathrm{abc}$ & $8,353 \mathrm{ab}$ & $1.13(0.109) \mathrm{bc}$ & 10,138 \\
\hline 9. Mod, Bulger at $I N F_{B u} \geq 0.70$ & $\ldots$ & $\ldots$ & 4 & 4 & $7.99(0.283) b c$ & $7,915 \mathrm{bc}$ & $1.61(0.129) \mathrm{c}$ & 10,004 \\
\hline 7. Mod, Broome at $I N F_{B r} \geq 0.80$ & 3 & $\ldots$ & 1 & 4 & $9.10(0.307) \mathrm{cd}$ & $8,135 \mathrm{ab}$ & $3.30(0.183) \mathrm{d}$ & 9,104 \\
\hline 1. Nontreated control & $\ldots$ & $\ldots$ & $\ldots$ & 0 & $12.41(0.360) \mathrm{d}$ & $7,077 \mathrm{c}$ & $3.55(0.189) \mathrm{d}$ & 9,237 \\
\hline$P$ value & $\ldots$ & $\ldots$ & $\ldots$ & $\ldots$ & $<0.001$ & 0.029 & $<0.001$ & 0.247 \\
\hline $\operatorname{LSD}(P \leq 0.05)$ & $\ldots$ & $\ldots$ & $\ldots$ & $\ldots$ & 0.065 & $1,000.6$ & 0.028 & \\
\hline \multicolumn{9}{|l|}{$2007-08$} \\
\hline 4. Mod, $\mathrm{Xu}$ at $I N F_{X_{u}} \geq 0.50$ & 11 & $\ldots$ & 3 & 14 & $1.00(0.100) \mathrm{a}$ & 6,289 & $0.49(0.070)$ & 6,789 \\
\hline 8. Mod, Bulger at $I N F_{B u} \geq 0.50$ & 6 & $\ldots$ & 2 & 8 & $1.82(0.134) \mathrm{ab}$ & 5,230 & $0.48(0.069)$ & 6,214 \\
\hline 3. Cal, Cap or Fen + Cap & 12 & $\ldots$ & 4 & 16 & $1.94(0.137) \mathrm{ab}$ & 5,787 & $0.37(0.064)$ & 6,001 \\
\hline 6. Mod, Broome at $I N F_{B r} \geq 0.62$ & 8 & $\ldots$ & 3 & 11 & $1.97(0.140) \mathrm{ab}$ & 5,869 & $0.43(0.068)$ & 6,482 \\
\hline 2. Cal, Cap & 16 & $\ldots$ & $\ldots$ & 16 & $1.95(0.141) \mathrm{abc}$ & 5,982 & $0.54(0.064)$ & 6,994 \\
\hline 9. Mod, Bulger at $I N F_{B u} \geq 0.70$ & $\ldots$ & $\ldots$ & 4 & 4 & $2.50(0.159) \mathrm{bcd}$ & 5,146 & $0.33(0.061)$ & 6,123 \\
\hline 5. Mod, $\mathrm{Xu}$ at $I N F_{X u} \geq 0.80$ & 9 & $\ldots$ & 3 & 12 & $2.99(0.165) \mathrm{bcd}$ & 6,007 & $0.63(0.082)$ & 5,883 \\
\hline 10. Mod, Bulger at $I N F_{B u} \geq 0.50$ and 0.70 & 6 & 2 & 2 & 10 & $3.12(0.177) \mathrm{bcd}$ & 5,361 & $0.30(0.056)$ & 5,938 \\
\hline 7. Mod, Broome at $I N F_{B r} \geq 0.80$ & 2 & $\ldots$ & 2 & 4 & $3.89(0.198) \mathrm{cd}$ & 5,830 & $0.65(0.082)$ & 6,338 \\
\hline 1. Nontreated control & $\ldots$ & $\ldots$ & $\ldots$ & 0 & $4.20(0.200) \mathrm{d}$ & 4,795 & $0.81(0.093)$ & 6,280 \\
\hline$P$ value & $\ldots$ & $\ldots$ & $\ldots$ & $\ldots$ & 0.039 & 0.238 & 0.571 & 0.536 \\
\hline $\operatorname{LSD}(P \leq 0.05)$ & $\ldots$ & $\ldots$ & $\ldots$ & $\ldots$ & 0.058 & & & \\
\hline \multicolumn{9}{|l|}{$2008-09$} \\
\hline 8. Mod, Bulger at $I N F_{B u} \geq 0.50$ & 2 & $\ldots$ & 1 & 3 & $0.54(0.075)$ & 9,150 & $0.35(0.060)$ & 12,668 \\
\hline 3. Cal, Cap or Fen + Cap & 13 & $\cdots$ & 4 & 17 & $0.56(0.077)$ & 9,688 & $0.23(0.052)$ & 13,077 \\
\hline 11.Mod, Bulger at $I N F_{B u} \geq 0.50$ and 0.70 & 1 & 1 & 2 & 4 & $0.87(0.090)$ & 9,047 & $0.42(0.061)$ & 12,549 \\
\hline 12. Mod to FWI, Bulger at $I N F_{\text {forecast }} \geq 0.50$ & 2 & $\ldots$ & 1 & 3 & $0.82(0.093)$ & 9,713 & $0.32(0.056)$ & 12,673 \\
\hline 2. Cal, Cap & 17 & $\ldots$ & $\ldots$ & 17 & $0.92(0.094)$ & 9,629 & $0.29(0.056)$ & 13,477 \\
\hline 1. Nontreated control & $\ldots$ & $\ldots$ & $\ldots$ & 0 & $1.34(0.115)$ & 8,644 & $0.50(0.074)$ & 12,316 \\
\hline$P$ value & $\ldots$ & $\ldots$ & $\ldots$ & 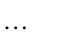 & 0.161 & 0.091 & 0.877 & 0.590 \\
\hline $\operatorname{LSD}(P \leq 0.05)$ & $\ldots$ & $\ldots$ & $\ldots$ & $\ldots$ & $\ldots$ & $\ldots$ & $\ldots$ & $\ldots$ \\
\hline
\end{tabular}

${ }^{\mathrm{x}}$ Mean percentages are reported, with the means of the transformed proportions in parenthesis.

y Cap = captan and Fen $=$ fenhexamid.

z Treatment numbers correspond to those defined in Table 1. Cal = calendar; Mod = model-timed; and Xu, Broome, and Bulger $=$ names of models used; LSD = least significant difference; FWI = forecast wetness interval. Weekly calendar treatments began on 15, 27, and 19 of November in the 2006-07, 2007-08, and 2008-09 seasons, respectively. Final calendar applications were on 28 February, 11 March, and 11 March in the 2006-07, 2007-08, and 2008-09 seasons, respectively. 
highest disease incidences within nontreated controls among the six examined.

Among all six season-cultivar trials, BFR incidence was highest in the nontreated control. The period with highest disease incidence during the 2006-07 season was between 30 January and 9 February 2007, with up to $47.9 \%$ for 'Sweet Charlie' and $10.7 \%$ for 'Strawberry Festival' (Fig. 1A and B). During this period, the $I N F_{B u} \geq 0.50$ treatment had about $50 \%$ lower disease incidence than the nontreated control. In the 2007-08 season, BFR incidence was highest for 'Sweet Charlie' (19.9\%) and 'Strawberry Festival' (6.5\%) on 29 February 2008 (Fig. 2A and B), following four consecutive days above the $I N F_{B u} \geq 0.50$ threshold (from 22 to 25 February 2008). In the 2008-09 season, disease incidence reached the maximum of 8.3 and $2 \%$ for the nontreated plots of 'Sweet Charlie' and 'Strawberry Festival', respectively, between 3 and 6 February 2009 (Fig. 3A and B). The 2008-09 season was marked by an unusual number of days with below-freezing temperatures, and only one fungicide spray was applied from mid-December until the end of the season for the $I N F_{B u} \geq 0.50$ treatment (Fig. 3).

Pairwise comparisons between means were conducted only for season-cultivar combinations where the overall treatment effect was significant at $P \leq 0.05$. In the three trials where pairwise comparisons of BFR incidences were analyzed, incidences in treatments with calendar applications of captan (treatment 2) or captan + fenhexamid (treatment 3$)$ were equivalent statistically $(P \leq 0.05)$ to the best treatment. Treatments where fungicides were applied using the disease models at the low threshold (treatments 4, 6, and 8) were equivalent statistically to the best treatment in the 2006-07 and 2007-08 trials on 'Sweet Charlie'. However, in the 2006-07 trial on 'Strawberry Festival', calendar applications of captan +

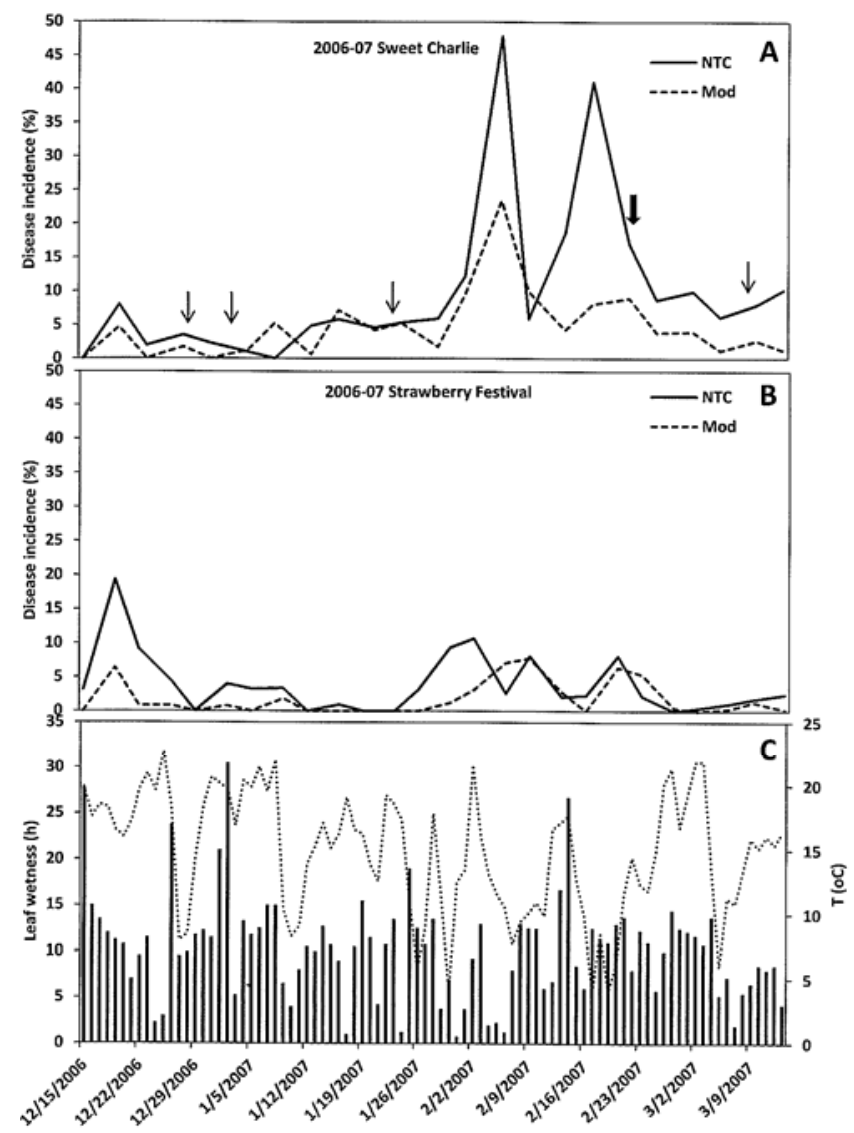

Fig. 1. Disease incidence in percentage for each evaluation date for A, 'Sweet Charlie' and B, 'Strawberry Festival' in the nontreated control (NTC) and the most effective model treatment $\left(I N F_{B u} \geq 0.50\right)$ (Mod) in the 2006-07 strawberry season. Smaller vertical arrows indicate the dates on which captan sprays were applied and darker arrows indicate the dates on which fenhexamid was applied. C, Leaf wetness duration (vertical bars) in continuous hours per day, and average temperature during the leaf wetness period (dashed line). fenhexamid provided better control than the low-threshold modeltimed applications $(0.5 \%$ for treatment 2 versus $1.6,1.0$, and $1.2 \%$ for treatments 4,6 , and 8 , respectively). In this trial, the nontreated control had $3.55 \%$ infected fruit. Disease incidences were higher in the nontreated control than in model-timed treatments using the low threshold in all trials where pairwise comparisons were made.

There were 16 fungicide applications for the calendar treatments (treatments 2 and 3) in 2006-07 and 2007-08 and 17 in 2008-09. The number of low-threshold timed applications using the $\mathrm{Xu}$ model was 12 in 2006-07 and 14 in 2007-08; with the Broome model, there were nine applications in 2006-07 and 11 in 2007-08; and, using the Bulger model, there were eight applications in 2006-07, eight in 2007-08, and three in 2008-09. During the first two seasons when all three models were compared, each of the three low-threshold, model-timed treatments (treatments 4, 6, and $8)$ were equivalent statistically $(P \leq 0.05)$.

For 'Sweet Charlie' in 2006-07 and 2007-08, disease incidence was greater for all three models when a higher threshold was used to time fungicide applications (treatments 4,6 , and 8 versus treatments 5, 7, and 9). For the Broome model, significant differences for disease incidence were observed between the low and the high thresholds in both seasons (treatment 6 versus 7). For the Bulger model, a significant effect for disease incidence was observed in 2006-07 (treatment 8 versus 9) and, for the Xu model, a significant effect was observed in 2007-08 (treatment 4 versus 5). For 'Strawberry Festival' in 2006-07, the BFR incidence was less for the Xu model-timed treatment when a high rather than a low threshold was used but the effect was not significant. For the Broome and Bulger models, BFR incidences were greater with the higher than the lower threshold and, for the Broome model, the effect was sig-

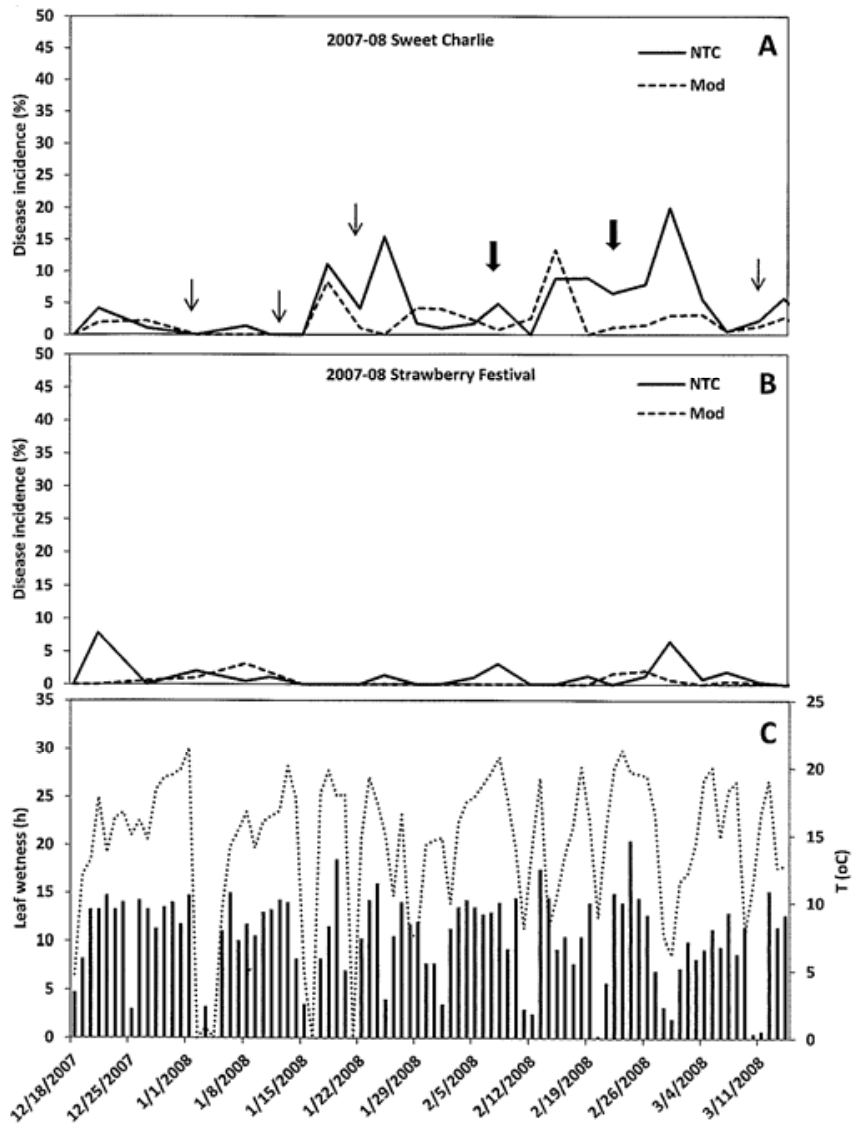

Fig. 2. Disease incidence in percentage for each evaluation date for $\mathbf{A}$, 'Sweet Charlie' and B, 'Strawberry Festival' in the nontreated control (NTC) and the most effective model treatment $\left(I N F_{B u} \geq 0.50\right)$ (Mod) in the 2007-08 strawberry season. Smaller vertical arrows indicate the dates on which captan sprays were applied and darker arrows indicate the dates on which fenhexamid was applied. C, Leaf wetness duration (vertical bars) in continuous hours per day, and average temperature during the leaf wetness period (dashed line). 
nificant (treatment 6 versus 7). The greater disease incidence observed when a higher threshold was used with the Bulger model occurred even with fenhexamid applied in addition to captan at all times in the high-threshold treatment. Reductions in the number of fungicide applications in high-threshold treatments based on the Broome and Bulger models were similar. During the 2006-07 and 2007-08 seasons, there were four fungicide applications in these treatments (treatments 7 and 9). There were 10 and 12 fungicide applications in the high-threshold treatment based on the Xu model (treatment 5) during the 2006-07 and 2007-08 seasons, respectively. The number of applications made using the higher threshold for this model was only slightly fewer than the 12 and 14 applications made at the low threshold. In addition, high-threshold applications using the Xu model exceeded the number of applications triggered by the low threshold for the Broome and the Bulger models. Although the higher threshold of the $\mathrm{Xu}$ model triggered more applications, BFR incidence was always higher in treatment 5 than in treatments 6 or 8 .

In 2006-07 and 2007-08, BFR incidence in treatment 10, where captan and fenhexamid were applied based on dual thresholds of the Bulger model, was equivalent to the treatment based on this model that used a low threshold and timed fenhexamid applications to the peak bloom (treatment 8). Although the incidences of BFR were statistically equivalent, in 2007-08, incidences for the dualthreshold treatment on 'Sweet Charlie' were not significantly different from the nontreated plots $(4.2 \%$ for treatment 1 versus and $3.1 \%$ for treatment 10 ). However, the effect was significant for the low-threshold treatment based on the Bulger model (treatment $8=1.8 \%)$.

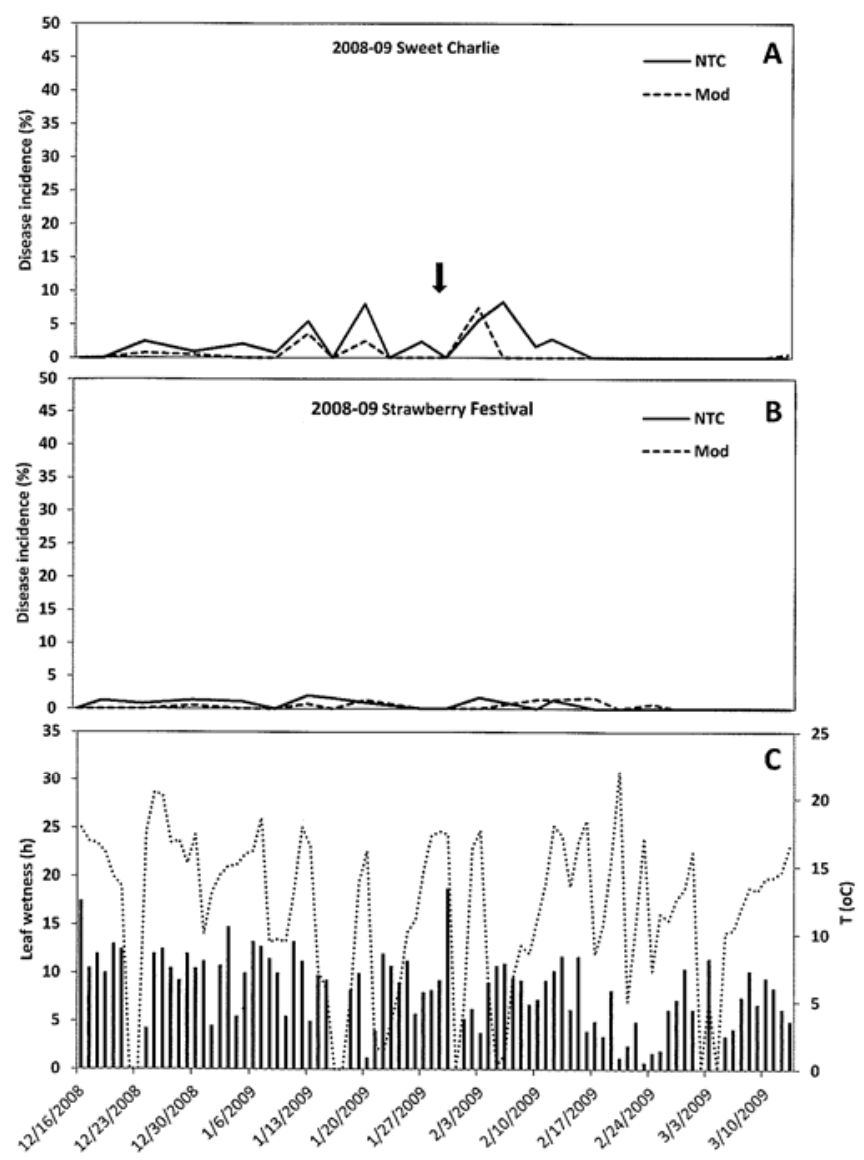

Fig. 3. Disease incidence in percentage for each evaluation date for A, 'Sweet Charlie' and B, 'Strawberry Festival' in the nontreated control (NTC) and the most effective model treatment $\left(I N F_{B u} \geq 0.50\right)$ (Mod) in the 2008-09 strawberry season. Smaller vertical arrows indicate the dates on which captan sprays were applied and darker arrows indicate the dates on which fenhexamid was applied. C, Leaf wetness duration (vertical bars) in continuous hours per day, and average temperature during the leaf wetness period (dashed line).
In 2008-09, there was no overall treatment effect significant at $P$ $\leq 0.05$ for either cultivar. The treatment using forecast weather to trigger applications for BFR using the Bulger model appeared to be effective. Even though there was no correlation between daily forecasted and actual leaf wetness duration, the extremes of dry or wet days and temperatures had a good correlation, and fungicide applications were either triggered at the same day or the day before when using the forecasted compared with the actual weather data. However, this treatment was only evaluated during one season when BFR incidence was low and no differences among any of the treatments were observed.

Yield effects. A treatment effect on total yield was only observed with 'Sweet Charlie' in 2006-07. Disease incidence was highest in this cultivar-season combination, with $12.4 \%$ in the nontreated control. Except for treatment 3, the calendar treatment with captan and fenhexamid, and treatment 9, the timed applications using the highest threshold of the Bulger model $\left(I N F_{B r} \geq\right.$ 0.80 ), all other treatments had significantly higher yields than the nontreated control.

\section{Discussion}

Results from our study indicate that BFR of strawberry fruit in Florida can be controlled effectively with fewer fungicide applications than are made at the present time. The $I N F_{B u} \geq 0.50$ (7) treatment reduced applications by 50,50 , and $82 \%$ in the $2006-07$, 2007-08, and 2008-09 seasons, respectively, compared with the calendar applications using the standard grower program of weekly fungicide sprays. With the exception of disease incidence in the 2006-07 season for 'Strawberry Festival', there were no significant differences in disease incidence or yield between the model-timed and calendar treatment programs. However, disease incidence was low for both treatments $(0.5 \%$ for treatment 3 versus $1.2 \%$ for treatment 8) in the 2006-07 season. The $I N F_{B r} \geq 0.62$ (5) performed as well as the $I N F_{B u} \geq 0.50$ (7) but required up to three more applications during the two seasons in which they were compared. In treatments using the $I N F_{X u} \geq 0.50$ (23), disease was reduced to levels similar to those observed with the other models but more fungicide applications were required. With 'Strawberry Festival' in 2007-08 and with both cultivars in 2008-09, disease incidence was low and none of the programs evaluated reduced disease compared with the nontreated control. Weather conditions unfavorable for disease development in 2008-09 (Fig. 2A-C) reflected the low number of fungicide applications dictated by the models. In the $I N F_{B u} \geq 0.50$ treatment, only three applications were required, two of them being applied before mid-December (Fig. 2A). Little disease developed on 'Strawberry Festival' in 2007-08, which may have been due to the fact that weather conducive to disease development coincided with periods when few flowers were present on plants. The Xu model (23) reduced fungicide applications while maintaining control of BFR in the United Kingdom (2). Under weather conditions in Florida, however, it did not improve disease control compared with the other models and only modestly reduced the number of fungicide applications relative to a calendar application program. The optimal temperature for flower infection as estimated by the Bulger model ( 7 ) is $20.5^{\circ} \mathrm{C}$. The Xu model was developed based on field conditions in the United Kingdom and temperatures may not have exceeded this optimum. Also, the $\mathrm{Xu}$ model assumes a linear correlation between nighttime temperature and disease development. In Florida, nighttime temperatures often exceeded the temperature optimum by two or three degrees. These deviations, rather than predicting reduced disease incidence, predicted higher levels of disease by the $\mathrm{Xu}$ model than would be predicted at the optimal temperature with all other variables being equal. For this reason, the Xu model often predicted events conducive to disease development when they did not exist and the model probably is not useful for forecasting BFR in subtropical strawberry production systems.

The systemic fungicide fenhexamid is more effective than captan at controlling BFR (15) but can be used only four times per season. Legard et al. (10) suggested that fenhexamid or other sin- 
gle-mode fungicides highly effective for control of BFR should be reserved for the peak bloom because this will prevent disease when fruit yields and disease incidence are highest. Thus, the use of captan early in the season followed by fenhexamid or another effective single-mode fungicides during peak bloom is a reasonable approach when making model-timed sprays. However, there are intervals during the peak bloom where weather conditions are clearly not favorable for disease development, making it unlikely that all four fenhexamid applications would be used during a season. For example, using the strategy of only applying fenhexamid during the peak bloom and the low threshold of the Bulger model $\left(I N F_{B u}\right.$ $\geq 0.50$ ) resulted in only two fenhexamid applications during the 2006-07 and 2007-08 seasons. Alternatively, a dual-threshold approach can be used, in which more effective fungicides are applied at a higher threshold. This has the advantage that the more effective fungicides can be employed when disease incidences are expected to be especially high throughout the season. Growers may benefit from this strategy, in that disease incidences would be reduced on fruit early in the season when prices are generally higher. The Bulger model was used to evaluate the dual-threshold strategy during the 2006-07 and 2007-08 seasons (treatment 10). On 'Sweet Charlie' in 2007-08, disease incidence was higher with the dual threshold strategy than when fenhexamid was applied only at peak bloom. The decreased disease control for the dual-threshold treatment likely occurred because, during the peak bloom, when yields were at their highest, fenhexamid was applied at the low threshold with the single-threshold treatment (treatment 8). In the dual-threshold treatment (treatment 10), only captan was applied during some of these intervals. Also, using the dual-threshold model resulted in more applications because fenhexamid alone was applied at the higher threshold if a low threshold event requiring a captan application occurred within 7 days.

Cultivars differ in their susceptibility to BFR. Our previous work has demonstrated that 'Sweet Charlie' is more susceptible to BFR than 'Strawberry Festival' $(9,18)$. Because disease incidence is generally lower on 'Strawberry Festival' than on 'Sweet Charlie', it may be possible to reduce even further the number of sprays for this partially resistant cultivar. One method of accomplishing this would be to increase the model threshold. Clearly, increasing the threshold for fungicide applications resulted in more disease on 'Sweet Charlie'. For 'Strawberry Festival', the results were not as clear. Treatment differences were significant for this cultivar only in the 2006-07 season. With the Bulger model, a combined application of captan and fenhexamid was used at the high threshold. For the low-threshold treatment, this combined application was made only during the peak bloom. Although the high-threshold treatment received a more effective fungicide early in the season, disease levels were higher in this treatment but not significantly different at $P \leq 0.05$. For the Broome model, the windows where fungicide applications could be made were the same and the high-threshold treatment also had higher disease. This suggests that, if significant disease occurs on the more resistant cultivar, some control will be lost with a higher threshold. Also, given that disease incidence is a function of the frequency of conducive weather events, it would be difficult to adjust applications for the more resistant cultivar by changing the threshold alone.

Model-timed applications for BFR could negatively affect yields if control of other fungal diseases was insufficient. The maximum incidence of anthracnose fruit rot in any treatment was less than $1 \%$; therefore, anthracnose had little effect on yields (unpublished). Timing fungicide applications to infection intervals for anthracnose infection using the model of Wilson et al. (22) also effectively controls anthracnose fruit rot if pyraclostrobin is incorporated into the spray program (12). Although there was very limited anthracnose fruit rot during the 2008-09 season, a treatment that timed fungicide applications to control BFR using the $I N F_{B u} \geq 0.50$ model and anthracnose fruit rot using the Wilson et al. (22) model was as effective as any treatment designed specifically to control BFR (unpublished). Captan is still an important tool for the integrated management of AFR and BFR but the number of applications of this fungicide can be significantly reduced when using the modeltimed program, and the single-mode and more effective fungicides can be saved for when weather conditions are highly favorable for disease development according to the disease models.

Our results for both cultivars and in all three seasons demonstrated that fungicide applications based on the $I N F_{B u} \geq 0.50$ threshold from the Bulger model (7) can be reduced without compromising disease control. Thus, a disease forecast webbased system has been established using leaf wetness duration and temperature data from the Florida Automated Weather Network system. The "Strawberry Advisory System" has been established on the AgroClimate website (http://agroclimate.org/ tools/strawberry) with specific recommendations for the management of BFR and AFR and is now available to Florida strawberry growers (16).

\section{Acknowledgments}

This project was funded in part by the United States Department of Agriculture Risk Management Agency. We thank T. Seijo, C. Moyer, J. Mertely, M. Hincapie, T. Hasing, J. Mangandi, N. Proaño, and J. Egenes for their technical assistance.

\section{Literature Cited}

1. Anscombe, F. J. 1948. The transformation of poisson, binomial and negative-binomial data. Biometrika 35:246-254.

2. Berrie, A. M., Harris, D. C., Xu, X.-M., and Burgess, C. M. 2002. A potential system for managing Botrytis and powdery mildew in main season strawberries. Acta Hortic. 567:647-649.

3. Braun, P. G., and Sutton, J. C. 1987. Inoculum sources of Botrytis cinerea in fruit rot of strawberries in Ontario. Can. J. Plant Pathol. 9:1-5.

4. Bristow, P. R., McNicol, R. J., and Williamson, B. 1986. Infection of strawberry flowers by Botrytis cinerea and its relevance to grey mould development. Ann. Appl. Biol. 109:545-554.

5. Broome, J. C., English, J. T., Marois, J. J., Latorre, B. A., and Aviles, J. C. 1995. Development of an infection model for Botrytis bunch rot of grape based on wetness duration and temperature. Phytopathology 85:97102 .

6. Brown, M. 2003. Florida strawberry production and marketing. Pages 31-42 in: The Strawberry: A Book for Growers, Others. N. F. Childers, ed. Dr. Norman F. Childers Publications, Gainesville, FL.

7. Bulger, M. A., Ellis, M. A., and Madden, L. V. 1987. Influence of temperature and wetness duration on infection of strawberry flowers by Botrytis cinerea and disease incidence of fruit originating from infected flowers. Phytopathology 77:1225-1230.

8. Chandler, C. K., Crocker, T. E., Price, J. F., and Albregts, E. E. 1994. Growing strawberries in the Florida garden. Proc. Fla. State Hortic. Soc. 107:397-399.

9. Chandler, C. K., Mertely, J. C., and Peres, N. A. 2006. Resistance of selected strawberry cultivars to anthracnose fruit rot and Botrytis fruit rot. Acta Hortic. 708:123-126.

10. Legard, D. E., MacKenzie, S. J., Mertely, J. C., Chandler, C. K., and Peres, N. A. 2005. Development of a reduced use fungicide program for control of Botrytis fruit rot on annual winter strawberry. Plant Dis. 89:1353-1358.

11. Legard, D. E., Xiao, C. L., Mertely, J. C., and Chandler, C. K. 2001. Management of Botrytis fruit rot in annual winter strawberry using captan, thiram and iprodione. Plant Dis. 85:31-39.

12. MacKenzie, S. J., and Peres, N. A. 2012. Use of leaf wetness and temperature to time fungicide applications to control anthracnose fruit rot of strawberry in Florida. Plant Dis. 96:522-528.

13. Mertely, J. C., MacKenzie, S. J., and Legard, D. E. 2002. Timing of fungicide applications for Botrytis cinerea based on development stage of strawberry flowers and fruit. Plant Dis. 86:1019-1024.

14. Mertely, J. C., and Peres, N. A. 2006. Botrytis fruit rot or gray mold of strawberry. PP-230/PP152, Department of Plant Pathology, Florida Cooperative Extension Service, IFAS, University of Florida. EDIS http://edis.ifas.ufl.edu/PP152.

15. Mertely, J. C., and Seijo, T. E. 2003. Evaluation of fungicides to control Botrytis fruit rot in annual strawberry, 2002-03. Fungic. Nematicide Tests Rep. 59:SMF020. Online publication. doi:10.1094/FN59.

16. Pavan, W., Fraisse, C. W., and Peres, N. A. 2011. Development of a webbased disease forecasting system for strawberries. Comput. Electron. Agric. 75:169-175.

17. Peres, N. A., and MacKenzie, S. J. 2009. Disease models for timing fungicide applications to control anthracnose and Botrytis fruit rots. Pages 36-38 in: Proc. N. Am. Strawberry Growers Assoc. 2009 Annu. Meet.

18. Seijo, T. E., Chandler, C. K., Mertely, J. C., Moyer, C., and Peres, N. A. 2009. Resistance of strawberry cultivars and advanced selections to anthracnose and Botrytis fruit rots. Proc. Fla. State Hortic. Soc.121:246-248.

19. Sutton, J. C. 1990. Epidemiology and management of Botrytis leaf blight of 
onion and gray mold of strawberry: a comparative analysis. Can. J. Plant Pathol. 12:100-110.

20. Sutton, J. C. 1998. Botrytis fruit rot (gray mold) and blossom blight. Pages 28-31 in: Compendium of Strawberry Diseases, 3rd ed. J. L. Maas, ed. American Phytopathological Society, St. Paul, MN.

21. Wilcox, W. F., and Seem, R. C. 1994. Relationship between strawberry gray mold incidence, environmental variables, and fungicide applications during different periods of the fruiting season. Phytopathology 84:264-270.

22. Wilson, L. L., Madden, L. V., and Ellis, M. A. 1990. Influence of temperature and wetness duration on infection of immature and mature strawberry fruit by Colletotrichum acutatum. Phytopathology 80:111-116.

23. Xu, X.-M., Harris, D. C., and Berrie, A. M. 2000. Modeling infection of strawberry flowers by Botrytis cinerea using field data. Phytopathology 90:1367-1374. 